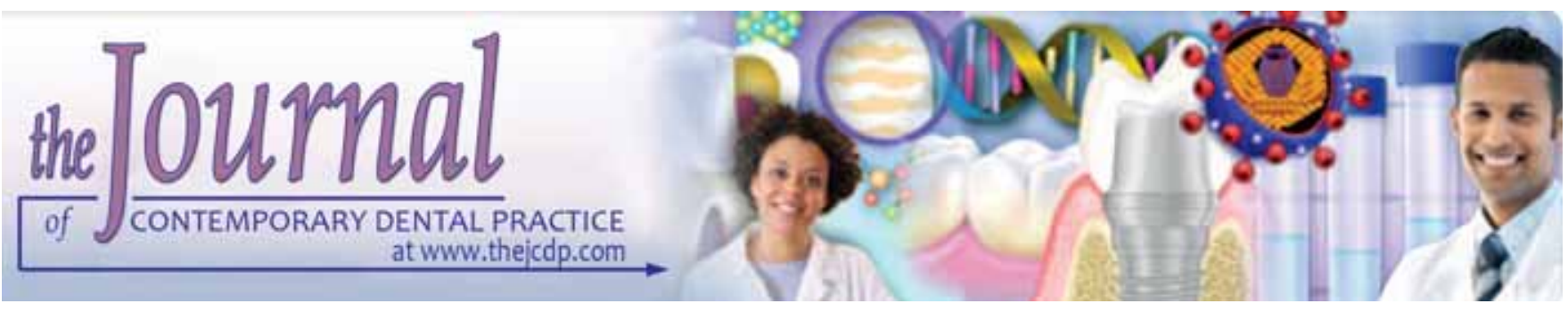

\title{
Pain during Root Canal Treatment: An Investigation of Patient Modifying Factors
}

\author{
Christopher I Udoye, Hamid Jafarzadeh
}

\begin{abstract}
Aim: The study highlighted the effect of patient-related factors on levels of pain felt by subjects during root canal treatment, as well as the association between treatment duration and pain severity.
\end{abstract}

Materials and methods: Maxillary central incisors with either necrotic pulp or irreversibly inflamed pulp, with or without preoperative pain were studied in 160 subjects aged 18 years and above. Subject's age and gender as well as pulp status and preoperative pain status were recorded. The procedure was done using a standard protocol. Visual analog scale was used to record the level of pain felt.

Results: Those cases with irreversible pulpitis felt higher pain. None with necrotic pulp experienced intense pain, while those in the 51 to 60 year age bands had severe, unbearable or intense pain. Mild pain was a common denominator in all age bands. Pain level increased with treatment duration.

Conclusion: Except for age, the level of pain felt by subjects during RCT is significantly correlated with gender and pulp status. Furthermore, the experienced pain levels increased with treatment duration.

Clinical significance: Clinicians should be prepared to make use of supplemental local anesthesia in women and in teeth with IP. All treatment must be accomplished within reasonable time period.

Keywords: Flare-up, Longitudinal study, Root canal therapy, Pain level.

How to cite this article: Udoye $\mathrm{Cl}$, Jafarzadeh $\mathrm{H}$. Pain during Root Canal Treatment: An Investigation of Patient Modifying Factors. J Contemp Dent Pract 2011;12(4):301-304.

\section{Source of support: Nil}

Conflict of interest: None declared

\section{INTRODUCTION}

Pain is legitimate report for the biology and psychology of a person. ${ }^{1}$ Endodontic-related pain may be pre-, intra- or postoperative in type. The work of Strindberg ${ }^{2}$ opened window of reports on the factors that may affect endodontic outcome. ${ }^{3}$ Pain perception is important to both the patient and the dentist; ${ }^{1}$ similarly, managing the pain and its distress can be frustrating. 4

The level of pain felt by subjects may vary according to gender and age of the subject and the pulp status. On the contrary, subjects may also respond in different ways to very similar levels of stimulus intensity. 5,6

Pain relief is the commonest reason for dental attendance. ${ }^{7}$ Most subjects perceive root canal treatment (RCT) to be a very painful procedure. However, it is reported that subjects who had experienced RCT are five times likely to describe the treatment as painless. ${ }^{8}$ The level of pain experienced by a subject may be subject-dependent.

A pulp may be necrotic or irreversibly inflamed. Some authors have found no significant association between necrotic pulp or irreversibly inflamed pulp (pulp status) and pain experienced during RCT. ${ }^{9}$ A local anesthetic may be ineffective in an irreversibly inflamed pulp. Jeske ${ }^{10}$ showed that neural hypersensitivity and challenges for the nerve fibers may become resistant to anesthetic agents. Meechan ${ }^{11}$ reported that in $80 \%$ of patients with irreversible pulpitis, the inferior alveolar block is ineffective. There is no consensus on the relationship between pain felt during root canal treatment and age. ${ }^{12}$ However, Watkins et $\mathrm{al}^{1}$ found that felt and anticipated pain levels decreased with increasing age. It is noteworthy that data on progressive loss of sensitivity to nociceptive stimuli with age is inconclusive. $^{13}$

While Watkins et $\mathrm{al}^{1}$ found that mean levels of pain experienced did not differ between genders; Unruh et $\mathrm{al}^{14}$ had a contrary report with women feeling more pain than men. Furthermore, the report is corroborated by Liddell et $\mathrm{al}^{15}$ who found a reduced pain threshold in women. There is a statistically higher level of mechanical allodynia in women with irreversible pulpitis. ${ }^{16}$ 
Literature on the current subject is scanty. Most times, the feeling of pain during RCT is inevitable. The successful management of such pain is both fundamental for practice building and endodontic outcome. ${ }^{7}$ If a clinician could predict the level of pain a patient may experience during RCT, he/she would be able to put in place measured mechanisms to enhance patient's management. The purpose of this study was to highlight the effect of patient-related factors, such as pulp status, subject's age and gender on levels of pain felt by subjects during RCT, and to investigate the association between length of treatment procedure, pain and severity.

\section{MATERIALS AND METHODS}

One hundred and sixty subjects aged 18 years or above were randomly recruited from both hospital and private clinics. While the Research and Ethics Committee of the University of Nigeria Technical Hospital approved the study, informed consent was obtained from subjects. Maxillary central incisors with necrotic pulp or irreversibly inflamed pulp, with or without preoperative pain, were recruited. Others were teeth with closed apices and those that had no apical radiolucency. Also, teeth that neither responded positively to electric pulp test (EPT) nor bled when opened were included.

Subjects with either systemic diseases or under 18 years, as well as those on either antibiotics in the last one month or on analgesics in the last 24 hours were excluded from the study. Others were nonfunctional teeth as well as teeth with massive calcifications.

The following information was recorded: Age and gender of subjects, pulp status (necrotic or irreversibly inflamed pulp) and preoperative pain status (painful or painfree). A periapical X-ray was used to assess the periapical status of teeth.
The subjects were prepared in the usual manner. Following a standard protocol, teeth were biomechanically prepared and sealed. The access cavity was restored with a light-cured nanohybrid composite (Nanosit, Navodiska Dental, Sweden).

Subjects were given visual analog scale (VAS) evaluation sheet on which they ranked the highest level of pain they experienced during treatment. VAS is a horizontal line, $10 \mathrm{~cm}$ in length. The numerical values of the pain levels were then converted to verbal scale of mild, severe, intense and unbearable pain descriptors.

Analysis of data was done with the SPSS for Windows, version 6 . Chi-square test was used to assess independence of categorical variables. The critical level of significance was set at $\mathrm{p} \leq 0.05$, while the confidence interval was $95 \%$.

\section{RESULTS}

There were 160 participants ( 89 men and 71 women) whose ages ranged from 18 to 61 years, except for mild pain, subjects with irreversible pulpitis (IP) those with necrotic pulp (NP). Most subjects (20 or 90.9\%) with IP had felt higher degrees of pain than severe pain, whereas no subject with NP had intense pain $(\mathrm{p}=0.002)$ (Table 1$)$.

No subject in the 51 to $60+$ year age bands had severe, unbearable or intense pain. Unbearable pain was seen in the 21 to 30 and 31 to 40 year age bands. Mild pain was common in all age bands. Similarly, excluding the 41 to 50 and 51 to $60+$ age bands, all other pain degree thought association is not statistically significant $(\mathrm{p}=0.49)$ (Table 2$)$. More women suffered the three worse pain levels most $(p=0.054)$ (Table 3).

As pain level increased, treatment duration increased while percentage of people who suffered worsening pain decreased. This is not applicable when intense pain is considered (Table 4).

\begin{tabular}{|c|c|c|c|c|c|}
\hline \multirow{3}{*}{ Pulp status } & \multirow{2}{*}{\multicolumn{4}{|c|}{ Intraoperative pain level (\%) }} & \multirow{3}{*}{ Total } \\
\hline & & & & & \\
\hline & Mild & Severe & Intense & Unbearable & \\
\hline \multirow{2}{*}{$\begin{array}{l}\text { Necrotic pulp } \\
\text { Irreversible pulpitis }\end{array}$} & $10(58.8)$ & $-(0)$ & $2(9.1)$ & $1(33.3)$ & $13(27.1)$ \\
\hline & 7 (41.2) & $6(100)$ & $20(09.9)$ & $2(66.7)$ & $35(72.9)$ \\
\hline \multicolumn{3}{|c|}{-value: $\mathrm{df}=3 ; \chi^{2}=14.57 ; p=0.002$} & & $48(100)$ & \\
\hline
\end{tabular}

\begin{tabular}{lcccc}
\multicolumn{5}{c}{ Table 2: Intraoperative pain by age } \\
\hline \multirow{2}{*}{ Age (Years) } & \multicolumn{4}{c}{ Intraoperative pain (\%) } \\
\cline { 2 - 5 } & Mild & Severe & Intense & Unbearable \\
\hline $18-20$ & $2(11.8)$ & $4(18.2)$ & $3(50.0)$ & $-(0)$ \\
$21-30$ & $5(29.4)$ & $4(18.2)$ & $2(33.3)$ & $1(33.3)$ \\
$31-40$ & $6(29.4)$ & $7(31.8)$ & $-(16.7)$ & $2(66.7)$ \\
$41-50$ & $3(17.6)$ & $7(31.8)$ & $-(0)$ & $-(0)$ \\
$51-60^{+}$ & $1(5.9)$ & $-(0)$ & & $-(0)$ \\
\hline
\end{tabular}

p-value: $d f=12 ; \chi^{2}=11.52 ; p=0.49$ 


\begin{tabular}{lcccc}
\multicolumn{5}{c}{ Table 3: Intraoperative pain by gender } \\
\hline & \multicolumn{4}{c}{ Intraoperative pain (\%) } \\
\cline { 2 - 5 } Mender & Mild & Severe & Intense & Unbearable \\
\hline Male & $10(58.8)$ & $9(40.9)$ & $-(0)$ & $1(33.3)$ \\
Female & $7(41.2)$ & $13(59.1)$ & $6(100)$ & $2(66.7)$ \\
\hline
\end{tabular}

p-value: $\mathrm{df}=3 ; \chi^{2}=6.44 ; p=0.054$

\begin{tabular}{|c|c|c|}
\hline Pain degree & $\begin{array}{c}\text { Treatment } \\
\text { duration (minutes) }\end{array}$ & $\begin{array}{c}\% \text { of subjects } \\
\text { who experienced pain }\end{array}$ \\
\hline Mild & 42 & 22 (37.9) \\
\hline Severe & 45.8 & $6(10.3)$ \\
\hline Intense & 46 & $17(29.3)$ \\
\hline Unbearable & 47 & $3(5.2)$ \\
\hline
\end{tabular}

\section{DISCUSSION}

The study of pain or its effect on a treatment outcome is usually frustrating; this is because human pain has many dimensions, including emotional and sensory aspects. Though pain perception is important to both patients and clinicians, ${ }^{17}$ perception may vary among subjects as people can express different emotional responses to very similar levels of stimulus intensity. 6,18

The present report agrees with that of Segura-Egea et $\mathrm{al}^{12}$ that there is statistically significant relationship between pulp status and pain level experienced during RCT. However, the above two reports disagree with others ${ }^{9,19}$ that had contrary findings. Segura-Egea et $\mathrm{l}^{12}$ found more pain in teeth with IP and acute apical periodontitis. This implies that a more profound anesthesia is required. Jeske ${ }^{10}$ showed that neural hypersensitivity is a challenge for the control of such pain as nerve fibers may become resistant to anesthetic agents.

Earlier reports to explore the effects of aging on pain experienced during treatment is inconclusive. The current study's finding of most statistically significant association between age and pain experienced during RCT is in agreement with that of Segura-Egea et al. ${ }^{12}$ However, Watkins et $\mathrm{al}^{1}$ reported that anticipated and experienced pain levels significantly decreased with advancing age. Agerelated decrease in pain is not thought to be attributable to changes in the physiological pain system. ${ }^{20}$ It was believed that prior experience with RCT could not account for this age effect. ${ }^{18}$ Rather Gibson et $\mathrm{al}^{21}$ showed that stoicism increases with age and potentially accounts for the lower pain reports. It is further reported that experienced pain levels increase in the final months of life. ${ }^{22}$

There are discrepancies in the literature on pain reports between men and women. ${ }^{20}$ The current study found a statistically significant association between gender and pain experienced during RCT, with more women experiencing more pain. Other reports had pointed out differences in pain perceptions between men and women. ${ }^{14}$ However, it is undoubtful that inconsistencies on degree of pain degree. ${ }^{17}$ It is thought that the perceived pain differences among genders may be due to the type of stimuli. ${ }^{23}$ In theirs, Unruh et $\mathrm{al}^{14}$ found that women anticipated higher pain levels than men, while Liddell et al ${ }^{15}$ reported an actual reduction of pain thresholds in women.

The finding of worsening pain in procedures that lasted shorter in the current study agrees with Segura-Egea's report. ${ }^{12}$ According to the latter's report, ${ }^{12}$ percentage of people who did not feel pain decreased as the length of the procedure increased. This may be due to progressive decrease in the effect of anesthesia. It may also be due to the increasing anxiety suffered by the subject as the intervention period is extended.

\section{CONCLUSION}

Except for age, the level of pain felt by subjects during RCT is significantly correlated with gender and pulp status. Furthermore, the experienced pain levels increased with treatment duration.

\section{CLINICAL SIGNIFICANCE}

Clinicians should be prepared to make use of supplemental local anesthesia in women and in teeth with IP. All treatment must be accomplished within reasonable time period.

\section{ACKNOWLEDGMENTS}

The authors would like to thank all who helped them in this research. This research was approved by Ethics on Human Research Committee of the College of Medicine University of Nigeria.

\section{REFERENCES}

1. Watkins CA, Logan HL, Kirchner HL. Anticipated and experienced pain associated with endodontic therapy. J Am Dent Assoc 2002;133:45-54.

2. Strindberg LZ. The dependence of the results of pulp therapy on certain factors: An analytic study based on radiographic and clinical follow-up examinations. Acta Odontol Scand 1956;14: 1-175.

3. Friedman S. Prognosis of initial endodontic therapy. Endod Topics 2002;2:59-88. 
4. Sathorn C, Parashos P, Messer H. The prevalence of postoperative pain and flare-up in single and multiple-visit endodontic treatment: A systematic review. Int Endod J 2008;41: 91-99.

5. Price DD. Psychological and neural mechanisms of the affective dimension of pain. Science 2000;288:1769-72.

6. Gracely RH, Kwilosz DM. The descriptor differential scale: Applying psychophysical principles to clinical pain assessment. Pain 1988;35:279-88.

7. Jariwala SP, Goel BR. Pain in endodontics: Causes, prevention and management. Endodontol 2001;13:63-66.

8. Public Communications Inc. Public knowledge and opinion about endodontics. A public opinion survey commissioned by the American Association of Endodontists, Chicago 1984.

9. Harrison JW, Gaumgartner JC, Svec TA. Incidence of pain associated with clinical factors during and after root canal therapy (Part 1). Interappointment pain. J Endod 1983;9:384-87.

10. Jeske AH. Local anesthetics: Special considerations in endodontics. J Tenn Dent Assoc 2003;83:14-18.

11. Meechan JG. Supplementary routes to local anaesthesia. Int Endod J 2002;35:885-96.

12. Segura-Egea JJ, Cisneros-Cabello R, Llamas-Carreras JM, Velasco-Ortega E. Pain associated with root canal treatment. Int Endod J 2009;42:614-20.

13. Walco GA, Harkins SW. Lifespan developmental approaches to pain. In: Gatchel RJ, Turk DC (Eds). Psychosocial factors in pain. New York: Guilford Press.

14. Unruh AM, Ritchie J, Merskey H. Does gender affect appraisal of pain and pain coping strategies? Clin J Pain 1999;15:31-40.

15. Liddell A, Locker D. Gender and age differences in attitudes to dental pain and dental control. Community Dent Oral Epidemiol 1997;25:314-18.

16. Khan AA, Owatz CB, Schindler WG, Schwartz SA, Keiser K, Hargreaves KM. Measurement of mechanical allodynia and local anesthetic efficacy in patients with irreversible pulpitis and acute periradicular periodontitis. J Endod 2007;33:796-99.

17. Eli I, Bar-Tal Y, Fuss Z, Korff E. Effect of biological sex differences on the perception of acute pain stimulation in the dental setting. Pain Res Manage 1996;1:201-06.

18. Price DD, Harkins SW, Baker C. Sensory-affective relationships among different types of clinical and experimental pain. Pain 1987;28:297-307.

19. Yesilsoy C, Koren LZ, Morse DR, Rankow H, Bolanos OR, Furst ML. Post-endodontic obturation pain: A comparative evaluation. Quintessence Int 1988;19:431-38.

20. Unruh AM. Gender variations in clinical pain experience. Pain 1996;65:123-67.

21. Gibson SJ, Katz B, Corran TM, Farrell MJ, Helme RD. Pain in older persons. Disabil Rehabil 1994;16:127-39.

22. Thomas MR, Roy R. The changing nature of pain complaints over the life span. New York: Plenum 1999.

23. Fillingim RB, Maixner W, Kincaid S, Silva S. Sex differences on temporal summation but not sensory-discriminative processing of thermal pain. Pain 1998;75:121-27.

\section{ABOUT THE AUTHORS}

\section{Christopher I Udoye}

Senior Lecturer, Endodontic Unit, Department of Restorative Dentistry, Faculty of Dentistry, College of Medicine, University of Nigeria, Nigeria

\section{Hamid Jafarzadeh (Corresponding Author)}

Assistant Professor, Department of Endodontics, Faculty of Dentistry and Dental Research Center, Mashhad, PO Box: 91735-984, Iran e-mail: hamid_j365@yahoo.com, jafarzadehBH@mums.ac.ir 